\title{
Efficacy of acupressure on nausea and vomiting among children with leukemia following chemotherapy
}

\author{
Youssria El-Sayed Yousef ${ }^{* 1}$, Nora Abd-Elhamid Zaki ${ }^{2}$, Amal Sayed ${ }^{3}$ \\ ${ }^{1}$ Departments of Pediatric Nursing, Faculty of Nursing, Sohag University, Sohag, Egypt \\ ${ }^{2}$ Departments of Pediatric Nursing, Faculty of Nursing, Assiut University, Assiut, Egypt \\ ${ }^{3}$ Departments of Pediatric Nursing, Faculty of Nursing, El-Minia University, El-Minia, Egypt
}

Received: May 29, 2018

DOI: $10.5430 /$ jnep.v9n1p89
Accepted: August 14, 2018

Online Published: September 17, 2018

\begin{abstract}
Background/Objective: Nausea and vomiting $(\mathrm{N} \& \mathrm{~V})$ remain the main side effects associated with cancer chemotherapy. This study determines the effect of acupressure on the control of $\mathrm{N} \& \mathrm{~V}$ among children with leukemia receiving chemotherapy.

Methods: This quasi-experiment study was conducted at two Pediatric Oncology Departments in South Egypt. Two groups of children with leukemia aging 6-18 years were included from October 2017 till March 2018. The study group $(n=60)$ received acupressure, while the control group $(n=60)$ didn't. All were subjected to socio-demographic and clinical interview questionnaire and Rhodes Index for N\&V Likert scale for assessment of frequency, duration, stress and severity of nausea and vomiting.

Results: Both groups had similar demographic data, were similar in diagnosis, disease severity, family history of neoplasia, and experienced similar chemotherapy-related side effects. Significant reduction of frequency, distress and severity of nausea and frequency, duration and severity of vomiting in addition to mean scores $\mathrm{N} \& \mathrm{~V}$ scale among children of the study group after application of acupressure when compared to children in the control group.

Conclusions: The application of acupressure at P6 in children with acute leukemia who were receiving chemotherapy led to significant reduction in the mean scores of $\mathrm{N} \& \mathrm{~V}$ in addition to their frequency, duration and severity within 48 hours from the beginning of chemotherapy in comparison to the control group. Therefore, acupressure techniques showed be used to reduce chemotherapy induced $\mathrm{N} \& \mathrm{~V}$ in children with leukemia.
\end{abstract}

Key Words: Acupressure, Nausea, Vomiting, Leukemia, Pediatric, Chemotherapy

\section{INTRODUCTION}

In developed countries, leukemia accounts for $30 \%$ of all cancers among children below 15 years of age, and is considered the most common childhood malignancy, where acute lymphoblastic leukemia (ALL) is the most predominant type representing $80 \%$ of all cases of leukemia. ${ }^{[1,2]}$

Despite being a global public health problem, in developing countries the image of leukemia in children is different from that in developed countries, where its incidence is increasing with variations in survival rates and in methods and time of diagnosis. Genetic and environmental risk factors and differences in diagnosis and treatment may play major role in this variation. ${ }^{[3]}$ In the USA, the incidence of childhood leukemia is 4.2 cases per 100,000 with a 5 -year survival rate of $82 \% .{ }^{[4]}$

Chemotherapy is considered the standard therapy for pa-

\footnotetext{
${ }^{*}$ Correspondence: Youssria El-Sayed Yousef; Email: saadzky@yahoo.com; Address: Departments of Pediatric Nursing, Faculty of Nursing, Sohag University, Sohag, Egypt.
}

Published by Sciedu Press 
tients with acute leukemia and other cancers with the purpose to control these diseases via suppressing the growth and spread of cancer cells. ${ }^{[5]}$ Chemotherapy-induced nausea and vomiting (CINV) are the most common side effects of chemotherapy with a prevalence of $54 \%-96 \%$ in addition to a list of other chemotherapy-related side effects in the pediatric oncology. ${ }^{[6]}$ Baker and Ellett (2007) reported that 59\% of teenagers with cancer stated that chemotherapy-related complications were more distressing than the cancer itself. ${ }^{[7]}$

CINV may have negative effects on the overall quality of life and represents a bad experience during cancer treatment. In addition, they can cause serious side effects including metabolic problems such as hyponatremia, hypokalemia and metabolic acidosis, inadequate nutritional intake leading to low resistance to infection and weight loss, depression, decreased self-care and its consequences, dehydration, difficulty with sleeping and anxiety. Also, patients with uncontrolled CINV require stay in the hospital for longer time and pay higher costs. ${ }^{[8,9]}$

The antiemetic drugs are prescribed to all patients with cancer and are considered the basic treatment to control CINV, however $30 \%-40 \%$ of cancer patients reported uncontrolled nausea and vomiting. ${ }^{[10]}$ In addition, the use of these drugs for a long time have undesirable side effects such as headaches, fatigue, diarrhea, constipation, dried mouth, confusion, drowsiness, agitation and extrapyramidal effects which add to the patients' problems itself. Therefore, search for other methods for controlling CINV represents a big challenge. So that, alternative and complementary medicine (CAM) attracted the attention of the healthcare providers and assumed significant importance in cancer therapy for reasons varying from accessibility to cost. ${ }^{[11-15]}$

Health is considered in traditional Chinese Medicine a state of harmony inside the individual and between the individual and surrounding nature and the disease is a state of disharmony. ${ }^{[16]}$ Disharmony is defined as any imbalance in the yin and yang and the connecting Qi. ${ }^{[17]}$ Yin and yang are a philosophical conceptualization of both opposite and complementary phenomena within all natural phenomena. Pathophysiology in humans is mainly explained by yin and yang principles of inter-connection and continuous transformation. Qi is the basal energy of the body that flows through the whole body in channels called meridians which is the basis for all movement and action. According to the theoretical Chinese belief, energy channels (meridians) link internal organs with the externally located acupoints. Stimulation of these acupoints regulates Qi, correcting both deficient and excessive conditions, in addition to regulating the nourishing and protective Qi, so balancing the yin and yang. ${ }^{[18]}$
Acupressure is a non-pharmacological method that was reported to play a role in reducing the incidence or controlling the severity of CINV. It can be performed easily via applying pressure with fingers or bands on certain points on the body surface called acu-points. In addition to its efficacy, acupressure is a simple, painless, and inexpensive approach. The Point 6 (P6) is one of these acu-points, which is located on the anterior surface of the forearm, 3-finger widths up from the first wrist crease and between the tendons of palmaris longus and flexor carpiradialis muscles. ${ }^{[19]}$

Zwaanswijk et al. (2010) stated that nurses who are dealing with cancer patients can be considered the cornerstone in alleviating the distressing load of chemotherapy-associated adverse effects being in close contact with those patients especially adolescents. Nurses must have wise communication skills with children and their families considering the differences in the social and educational levels, age, culture, and experience with chemotherapy. In addition, the meticulous assessment of children with cancer will help them to ensure the administration of the suitable antiemetic therapy and encourage children and their parents for better application and adherence to acupressure to optimize the outcomes of therapy. ${ }^{[20]}$

Identifying methods to successfully prevent and alleviate CINV remains a major clinical challenge. Moreover, it has been observed over a period of clinical practice with nursing students in clinical oncology department that many nurses had a poor knowledge about CINV and how to manage. More than $90 \%$ of cancer patients receiving chemotherapy without antiemetic prophylaxis will suffer from nausea and vomiting. ${ }^{[21,22]}$ In addition, antiemetic medications are not effective in all children receiving chemotherapy and with many side effects. Non pharmacological management of CINV is considered a neglected area for both physicians and nurses such as acupressure, acupuncture, and herbal medicine. Acupressure of the $\mathrm{P} 6$ point had proven helpful with promising effect in some patients in controlling CINV and the effect lasted for 6-8 hours. ${ }^{[23-25]}$ Combining antiemetic therapy with other non-pharmacological interventions may be more effective in decreasing nausea and vomiting than antiemetic therapy alone.

The main objective of this study was to determine the effect of acupressure on nausea and vomiting among children with leukemia receiving chemotherapy. In other words, this study tests the hypothesis that the application acupressure at P6 point in children with leukemia who are receiving chemotherapy will result in less incidence and lower severity of nausea and vomiting than those patients who are receiving only routine hospital care. 


\section{Methods}

\subsection{Study design}

A Quasi-experimental study was used.

\subsection{Settings}

The study was conducted at the Pediatric Oncology Department, South Egypt Cancer Institute in Assiut University and in the Pediatric Oncology Department, Sohag Cancer Center, Sohag Governorate, Egypt.

\subsection{Subjects}

A total of 120 children with acute leukemia who were selected from the previous two settings were included. They were divided into two groups namely: The Study Group ( $\mathrm{n}=$ $60)$ that received routine hospital care in addition to application of acupressure technique at P6; and The Control Group $(n=60)$ who received routine hospital care only.

\subsubsection{Inclusion criteria}

Children aged 6-8 years who have leukemia, and were hospitalized for at least 3 days to receive chemotherapy.

\subsubsection{Exclusion criteria}

Children were excluded from the study if they have disturbed level of consciousness, gastrointestinal and nervous system cancers, injury at the pressure area, and if they are under radiation.

\subsection{Tools of the study}

Two tools were used in this study:

1) Tool I: A demographic and clinical data interview questionnaire. It was developed by the researcher after reviewing literature and consists of socio-demographic variables (age, sex, residence, and family history of neoplasia) and clinical data (child's diagnosis, stage of disease and side effects of chemotherapy). The developed questionnaire was tested for content validity by 5 experts; 3 in the field of Pediatric Nursing and 2 in Pediatric Medical Oncology, and any needed modifications were done accordingly.

2) Tool II: Rhodes scale for Nausea and Vomiting: It was developed by Rhodes and McDanial in 1995, ${ }^{[26]}$ and measures the severity, frequency, and distress of nausea and vomiting within 48 hours after the beginning of chemotherapy. It was translated into Arabic to assess Egyptian children and was modified by Hassan et al. (2011). ${ }^{[27]}$ The scale consists of 6 questions in the form of 5 points Likert scale to assess the number of vomiting episodes per day, the quality and quantity of vomiting, degree and length of nausea, as well as the distress associated with nausea and vomiting every 12 hours for 48 hours from the beginning of chemotherapy induction. The scoring system is graded as follows: $0=$ none; $1=$ mild;
$2=$ moderate; $3=$ severe; $4=$ very severe. Reliability of tools II was done using the Cronbach's alpha test to examine the internal consistency, and was found to be 0.93 .

\subsection{Procedures}

A pilot study was carried out to evaluate the clarity and applicability of tools on 12 children; 6 patients for each group. No changes were done in the assessment sheet, so the 12 children selected for the pilot study were included in the main study. Assessment of children condition was done by the researchers through using tools I \& II for both control and study group. The researchers were trained by physical therapist at Assiut University Hospital for 7 days to do the acupressure technique successfully through practice and watching video and photo. The current study started from the beginning of October 2017 till the end of March 2018. Pressure point P6 also called Neiguan, is located on the inner arm near your wrist. Nausea and vomiting indices were measured in Study and Control Groups every 12 hours for 48 hours from the beginning of chemotherapy. Acupressure on this point was done using the following steps:

(1) Position your hand so that your fingers are pointing up and your palm is facing you.

(2) To find pressure point P-6, place the first 3 fingers of your opposite hand across your wrist (see Figure 1).

(3) Place your thumb on the inside of your wrist just below your index finger (see Figure 2). You should be able to feel 2 large tendons under your thumb. This point is called point $\mathrm{P}-6$.

(4) Use your thumb or forefinger to press on this point for 2 to 3 minutes using a circular motion. Be firm, but don't press so hard that it hurts. The acupressure program consisted of $3 \mathrm{~min}$ of acupressure on point P6 on both sides of the body. Each child received three consecutive intervention sessions: the 1st session was 30 minutes before the start of chemotherapy, the 2nd session was before dinner on the day of chemotherapy, and the 3rd session was before breakfast the next day. The intervention sessions were done by the same researcher.

\subsection{Ethical considerations}

The research proposal was approved from Ethical Committee in the Faculty of Nursing, Assiut University. Both confidentiality and anonymity were assured. An informed consent from parents of participating children was obtained after explaining the nature and purpose of the study. The children and their parents had the right to refuse to participate or withdraw from the study without any rational any time. The privacy of the participating children was considered during 
collection of data. After the last evaluation of study group, of Social Sciences (SPSS) version 19 (SPSS Inc, Chicago children of the control group received the acupressure technique to relieve their symptoms of nausea and vomiting.

\subsection{Statistical analysis}

Date were collected in a preformed data collection form before being entered and analyzed using the Statistical Package

IL, USA). Data were presented as number, percentage, mean, standard deviation (SD). Chi-square was used to compare between qualitative variables. Mann-Whitney-U test was used to compare quantitative variables between two groups. A $p$-value of $<.05$ was considered statistically significant.

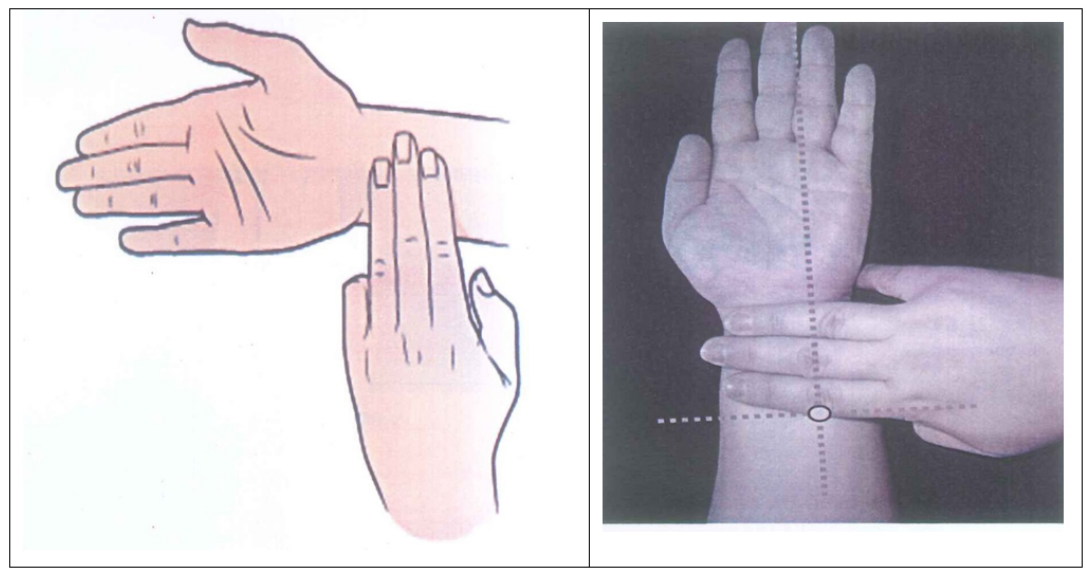

Figure 1. Placing 3 fingers across wrist

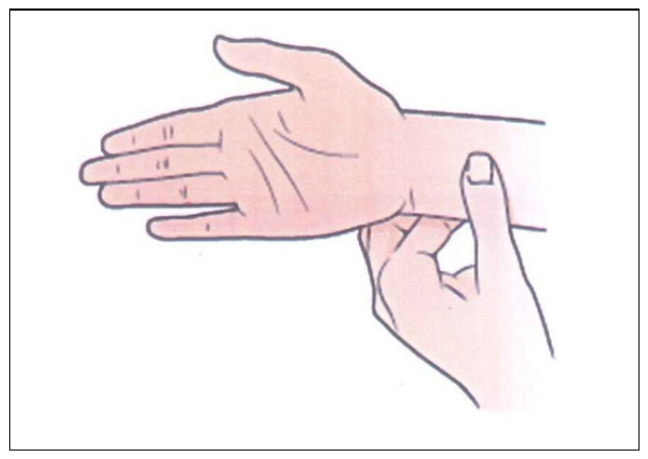

Figure 2. Placing thumb on point below index finger

\section{Results}

Table 1 shows that children in control and study groups are well matched regarding their demographic characteristics and no statistical significant difference were found regarding their age, sex and residence.

Table 2 shows that both control and study groups were matched regarding type and duration of leukemia, stage of disease, family history of oncological diseases and side effects of chemotherapy.

Table 3 represents comparison between control and study groups regarding the items of Rhodes index of nausea and vomiting scale during 48 hours following chemotherapy administration. There was highly significant improvement of the frequency, distress and severity of nausea and frequency, duration and severity of vomiting among children of the study group after application of acupressure when compared to children in the control group $(p=.000)$.

Table 1. Socio-demographic characteristics of children in control and study groups

\begin{tabular}{llll}
\hline Variable & Categories & Control Group (n = 60) & Study Group (n= 60) \\
\hline \multirow{2}{*}{ Age (years) } & $6-<8$ & $37(61.7 \%)$ & $34(56.7 \%)$ \\
& $8-<12$ & $13(21.7 \%)$ & $15(25.0 \%)$ \\
& $12-\leq 18$ & $10(16.6 \%)$ & $11(18.3 \%)$ \\
Sex & Mean \pm SD & $8.08 \pm 3.72$ & $7.96 \pm 3.82$ \\
& Male & $37(61.7 \%)$ & $41(68.3 \%)$ \\
Residence & Female & $23(38.3 \%)$ & $19(31.7 \%)$ \\
& Rural & $42(70.0 \%)$ & $51(85.0 \%)$ \\
\hline
\end{tabular}


Table 2. Comparison of control and study groups regarding characteristics of leukemia and side effects of chemotherapy

\begin{tabular}{|c|c|c|c|c|}
\hline Variable & Categories & $\begin{array}{l}\text { Control Group } \\
(n=60)\end{array}$ & $\begin{array}{l}\text { Study Group } \\
(n=60)\end{array}$ & $p$ value \\
\hline \multirow{2}{*}{ Diagnosis } & ALL & $53(88.3 \%)$ & $56(93.3 \%)$ & \multirow{2}{*}{.526} \\
\hline & AML & $7(11.7 \%)$ & $4(6.7 \%)$ & \\
\hline \multirow{3}{*}{ Stage of disease } & Induction & $12(20.0 \%)$ & $8(13.3 \%)$ & \multirow{3}{*}{.404} \\
\hline & Remission & $45(75.0 \%)$ & $46(76.7 \%)$ & \\
\hline & Relapse & $3(5.0 \%)$ & $6(10.0 \%)$ & \\
\hline \multirow{2}{*}{ Family history of neoplasia } & Positive & $20(33.3 \%)$ & $18(30.0 \%)$ & \multirow{2}{*}{.792} \\
\hline & Negative & $40(66.7 \%)$ & $42(70.0 \%)$ & \\
\hline \multirow{8}{*}{ Side effects of chemotherapy } & Diarrhea & $32(53.3 \%)$ & $60(100 \%)$ & .354 \\
\hline & Nausea/vomiting & $60(100 \%)$ & 49 (81.7\%) & 1.000 \\
\hline & Alopecia & 55 (91.7\%) & $48(80.0 \%)$ & .178 \\
\hline & Anorexia & 45 (75.0\%) & $14(23.3 \%)$ & .662 \\
\hline & Bleeding & $14(23.3 \%)$ & $22(36.0 \%)$ & .829 \\
\hline & Infection & $18(30.0 \%)$ & $60(100 \%)$ & .613 \\
\hline & Fatigue & $60(100 \%)$ & $56(93.3 \%)$ & 1.000 \\
\hline & Mouth sores & $52(86.7 \%)$ & $60(100 \%)$ & .367 \\
\hline
\end{tabular}

Note. ALL: Acute lymphoblastic leukemia. AML: Acute myeloid leukemia.

Table 3. Percentage distribution of children according to items of Rhodes index of nausea and vomiting scale during 48 hours following chemotherapy administration

\begin{tabular}{|c|c|c|c|c|}
\hline Variable & Categories & $\begin{array}{l}\text { Control Group } \\
(n=60)\end{array}$ & $\begin{array}{l}\text { Study Group } \\
(\mathrm{n}=60)\end{array}$ & $p$ value \\
\hline \multirow{5}{*}{ Vomiting frequency } & No & $26(43.3 \%)$ & $48(80.0 \%)$ & \multirow{5}{*}{.000} \\
\hline & Mild (1-2) & $29(48.3 \%)$ & $9(15.0 \%)$ & \\
\hline & Moderate (3-4) & $5(8.3 \%)$ & $3(5.0 \%)$ & \\
\hline & Great (5-6) & $0(0.0 \%)$ & $0(0.0 \%)$ & \\
\hline & Severe $(\geq 7)$ & $0(00 \%)$ & $0(00 \%)$ & \\
\hline \multirow{5}{*}{ Vomiting distress } & No & $22(36.7 \%)$ & $57(95.0 \%)$ & \multirow{5}{*}{.000} \\
\hline & Mild & $31(51.7 \%)$ & $3(5.0 \%)$ & \\
\hline & Moderate & $7(11.6 \%)$ & $7(11.6 \%)$ & \\
\hline & Great & $0(0.0 \%)$ & $0(0.0 \%)$ & \\
\hline & Severe & $0(00 \%)$ & $0(00 \%)$ & \\
\hline \multirow{5}{*}{ Vomiting severity } & No & $09(15.0 \%)$ & $48(80.0 \%)$ & \multirow{5}{*}{.000} \\
\hline & Small (up to $1 / 2$ cup) & $45(75.0 \%)$ & $10(16.7 \%)$ & \\
\hline & Moderate ( $1 / 2-2$ cups) & $6(10.0 \%)$ & $2(3.3 \%)$ & \\
\hline & Large (2-3 cups) & $0(0.0 \%)$ & $0(0.0 \%)$ & \\
\hline & Very large ( $>3$ cups) & $0(00 \%)$ & $0(00 \%)$ & \\
\hline \multirow{5}{*}{ Nausea duration } & No & $11(18.3 \%)$ & $54(90.9 \%)$ & \multirow{5}{*}{.000} \\
\hline & Mild ( $\leq 1$ hour) & $41(68.3 \%)$ & $5(8.3 \%)$ & \\
\hline & Moderate (2-3 hours) & $6(10.0 \%)$ & $1(1.7 \%)$ & \\
\hline & Great (4-5 hours) & $2(3.3 \%)$ & $0(0.0 \%)$ & \\
\hline & Severe ( $\geq 6$ hours) & $0(0.0 \%)$ & $0(00 \%)$ & \\
\hline \multirow{5}{*}{ Nausea severity } & No & $11(18.3 \%)$ & $57(95.0 \%)$ & \multirow{5}{*}{.000} \\
\hline & Mild & $43(71.7 \%)$ & $3(5.0 \%)$ & \\
\hline & Moderate & $6(10.0 \%)$ & $0(0.0 \%)$ & \\
\hline & Great & $0(0.0 \%)$ & $0(0.0 \%)$ & \\
\hline & Severe & $0(00 \%)$ & $0(00 \%)$ & \\
\hline \multirow{5}{*}{ Nausea frequency } & No & $13(21.7 \%)$ & $54(90.0 \%)$ & \multirow{5}{*}{.000} \\
\hline & Mild (1-2) & $42(70.0 \%)$ & $4(6.7 \%)$ & \\
\hline & Moderate (3-4) & $3(5.0 \%)$ & $2(3.3 \%)$ & \\
\hline & Great (5-6) & $2(3.3 \%)$ & $0(0.0 \%)$ & \\
\hline & Severe $(\geq 7)$ & $0(0.0 \%)$ & $0(00 \%)$ & \\
\hline
\end{tabular}


Table 4 shows that, when the mean scores of the items of Rhodes scale for nausea and vomiting were measured during 48 hours following chemotherapy administration, there was highly significant reduction among children of the study group in comparison to children in the control group indicating the significant positive effect of the application of acupressure $(p=.000)$.

Table 4. Comparison between control and study groups regarding the mean scores of items of Rhodes Scale for nausea and vomiting scale during 48 hours following chemotherapy administration

\begin{tabular}{|c|c|c|c|c|}
\hline Variable & Categories & $\begin{array}{l}\text { Control Group } \\
(\mathrm{n}=60)\end{array}$ & $\begin{array}{l}\text { Study Group } \\
(\mathrm{n}=\mathbf{6 0})\end{array}$ & $p$ value \\
\hline \multirow{3}{*}{ Vomiting } & Frequency & $0.14 \pm 0.27$ & $0.49 \pm 0.48$ & .000 \\
\hline & Distress & $0.03 \pm 0.11$ & $0.47 \pm 0.50$ & .000 \\
\hline & Severity & $0.08 \pm 0.21$ & $0.85 \pm 0.64$ & .000 \\
\hline \multirow{3}{*}{ Nausea } & Duration & $0.05 \pm 0.19$ & $0.77 \pm 0.51$ & .000 \\
\hline & Severity & $0.17 \pm 0.38$ & $0.57 \pm 0.46$ & .000 \\
\hline & Frequency & $0.07 \pm 0.17$ & $0.69 \pm 0.49$ & .000 \\
\hline
\end{tabular}

Figure 3 shows comparison of the total mean scores of Rhodes scale for nausea and vomiting between control and study groups every 12 hours within 48 hours following chemotherapy administration. There was highly significant reduction of the mean scores starting after the 1 st 12 hours and continued till the end of 48 hours following chemotherapy administration using Mann-Whitney test $(p=.000)$.

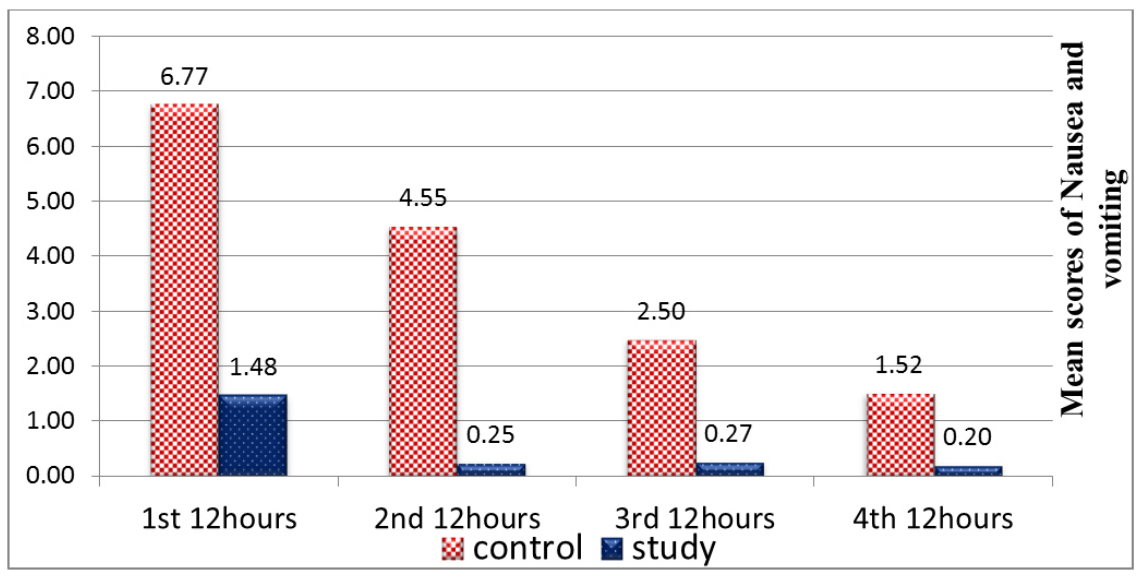

Figure 3. Comparison between control and study groups regarding to the mean scores of Rhodes scale for nausea and vomiting scale during 48 hours following chemotherapy administration every 12 hours

\section{Discussion}

CINV are the most difficult symptoms to deal with in clinical practice. According to the fact that, antiemetic drugs are not effective in all cancer patients under chemotherapy to control CINV, it is mandatory to search for another approaches either alternative or adjuvant to antiemetic drugs. The nonpharmacological therapies are one of such approaches. Acupressure as one of the non-pharmacological therapies showed a positive effect in control of CINV in adult and pediatric oncology. ${ }^{[28]}$

In the present study, about two thirds of children in control and study groups had negative family history while about one third had positive family history of oncological diseases.
These results are consistent with the results of Salama et al. (2011) who found that, two thirds of children with leukemia had negative family history of cancer. ${ }^{[29]}$ Meanwhile et al. (2001) reported higher percentage of children with acute leukemia (about 50\%) with positive family history of oncological disorders. ${ }^{[30]}$

In the current study, application of acupressure at P6 in children with acute leukemia and under chemotherapy achieved highly statistically significant reduction of the frequency, distress and severity of nausea and frequency, duration and severity of vomiting within 48 hours from beginning of chemotherapy administration in comparison to the control group. 
Many studies in different countries evaluated the acupressure as a simple method for management of CINV in not only in children with leukemia but also in various types of cancer. The results of the current study are consistent with and supported by the results of several studies. Dibble et al. (2007) found that, advising the patients to apply acupressure on the P6 point for 3-5 min every day before chemotherapy or once before each meal for 5-21 days significantly reduced the frequency, duration, and severity of CINV. ${ }^{[28]}$ Gardani et al. (2007) and Said (2009) assessed the effect of acupressure in P6 area on CINV in patients with breast cancer and found that, acupressure with wristband influences nausea and vomiting delayed phase but no influence on the acute phase. ${ }^{[31,32]}$ Sima and Wang (2009) reported that, the acupressure led to significant reduction in the intensity of nausea and the vomiting amount in the delayed phase. ${ }^{[33]}$

Also, Ryan et al. (2010) studied the role of acupressure in P6 area in the prevention of CINV and suggested that, in order to prevent nausea and vomiting, acupressure should be started some days before chemotherapy. ${ }^{[34]}$

Similarly, Hussein and Abdel Sadek, (2013) evaluated the effect acupressure on chemotherapy-induced vomiting among 50 children with leukemia in Egypt and stated that, acupressure could be an effective method in the management of vomiting associated with chemotherapy in children with leukemia. ${ }^{[23]}$

In the same way, Esmail et al. (2014) studied 90 children aged 7-18 years with ALL under chemotherapy at Tanta governorate in Egypt and concluded that, the mean scores of nausea and vomiting were lower among children receiving acupressure technique than those receiving routine hospital care. ${ }^{[35]}$ Chuang et al. (2014) and Ezzo et al. (2014) investigated the effect of acupressure on CINV in cancer patients and reported that the it reduced nausea severity. ${ }^{[36,37]}$ Genc and Tan (2015) reported that, acupressure decreased CINV and anxiety in patients with breast cancer. ${ }^{[38]}$

Abusaad and Ali (2016) studied the effect of acupressure among 60 adolescents with leukemia who received chemotherapy in Egypt and found significant reduction of the frequency, duration and severity of nausea, vomiting and retching in comparison with control group. ${ }^{[39]}$

Shen and Yang (2017) concluded that, acupressure significantly increased the mean meridian energy and effectively decreased the severity of nausea and vomiting in lung cancer patients undergoing chemotherapy and recommend that, clinical nurses should provide acupressure as an intervention to relieve nausea and vomiting in patients receiving chemotherapy. ${ }^{[40]}$
Byju et al. (2018) evaluated the effectiveness of acupressure on the experience of nausea and vomiting among patients receiving chemotherapy and concluded that, acupressure is an effective method for reducing nausea and vomiting among patients receiving chemotherapy. ${ }^{[41]}$

Many studies tried to explain how acupressure on certain points improve CINV and reported that acupressure application on the affected meridians on the body surface could increase the flow of energy, boost meridian energy, improve blood circulation and promote the recovery of gastrointestinal function and hence effectively reduce CINV. ${ }^{[28,37]}$

Shen and Yang (2017) concluded that nurses can independently do acupressure and also can teach the patients to carry out the procedure by themselves. They added that, the development of acupressure as a nursing intervention, dependent on a theoretical concept, evidence based studies, and practical nursing experience represents a very important step for the future of the nursing care of cancer patients undergoing chemotherapy. ${ }^{[40,41]}$

In contrast with results of the current study, Wulffa et al. (2009) stated that, no significant benefit was experienced with children who were subjected to acupressure in the control of CINV. ${ }^{[42]}$ Also contradictory to the present study findings a single blinded randomized trial was conducted by Genc et al. (2013) on the efficiency of acupressure in the prevention of CINV among 120 patients with breast, gynecological, and lung cancers. They concluded that, the acupressure wristband was not an effective approach in preventing CINV. This difference could be due to the variation in sample size, diagnosis of cancer and socio-cultural differences. ${ }^{[25]}$

The results of the present study revealed no statistically significant relations between the mean scores of nausea and vomiting and age, sex and different stages of disease. These results matched with those of Hussein and Abdel Sadek (2013) who reported that there is no relation between sex, age and frequency of nausea and vomiting. ${ }^{[43]}$ Also, Mohammed et al. (2015) found that no relation between gender and severity of nausea although females tended to have more severe vomiting than males. ${ }^{[43]}$

On the other hand, this results disagree with those of Esmail et al. (2014) who found a highly statistically significant relation between sex, age, and severity of acute and delayed nausea and vomiting (girls had severe acute nausea and vomiting compared to boys, and younger children had reached a severe level of nausea and vomiting compared to older children). ${ }^{[35]}$ 


\section{Conclusion}

In conclusion, the application of acupressure technique in children with acute leukemia who were receiving chemotherapy led to a significant reduction in the mean scores of nausea and vomiting as well as their frequency, duration, and severity within 48 hours from the beginning of chemotherapy in comparison to children who received routine hospital care only. Therefore, acupressure should be carried out as a supportive nursing intervention to relieve CINV in children with cancer and before the start of chemotherapy. In addition, edu- cational programs should be provided in order to increase the knowledge and skills of health-care professionals in applying acupressure in their management plans. This includes supplying simplified booklets about acupressure, which should be available for children and their families in Chemotherapy Administration Units together with a given instruction from nurses or other health-care professionals.

\section{CONFliCtS OF INTEREST Disclosure}

There is no conflict of interest of any type associated with this study.

\section{REFERENCES}

[1] Metayer C, Milne E, Clavel J, et al. The Childhood Leukemia International Consortium. Cancer Epidemiol. 2013 Jun; 37(3): 336-47.

[2] Shalal HH, Mahmood NS, Alchalabi MA. Clinical, hematological, and laboratory presentation of acute lymphoblastic leukemia of children in Diyala province/Eastern Iraq. Int J Res Med Sci. 2017 Oct; 5(10): 4227-33.

[3] Demanelis K, Sriplung H, Meza R, et al. Differences in childhood leukemia incidence and survival between Southern Thailand and the United States: a population-based analysis. Pediatr Blood Cancer 2015 Oct; 62(10): 1790-8.

[4] Howlader N, Noone AM, Krapcho M, et al. SEER Cancer Statistics Review, 1975-2012, National Cancer Institute. Bethesda, MD Available from: https://seer.cancer.gov/csr/1975_2012/

[5] Prapti NKG, Petpichetchian W, Chongcharoen W. Development of Foot Massage Program on Nausea and Vomiting for Cancer Patients: A Literature Review. Nurse Media J Nursing. 2012; 2(1): 325-35.

[6] Pirri C, Katris P, Trotter J, et al. Risk factors at pretreatment predicting treatment-induced nausea and vomiting in Australian cancer patients: a prospective, longitudinal, observational study. Support Care Cancer. 2011 Oct; 19(10): 1549-63.

[7] Baker PD, Ellett ML. Measuring nausea and vomiting in adolescents: a feasibility study. Gastroenterol Nurs. 2007 Jan-Feb; 30(1): 18-28. PMid:17312421 https://doi .org/10.1097/00001610-20070 1000-00002

[8] Taspinar A, Sirin A. Effect of acupressure on chemotherapy-induced nausea and vomiting in gynecologic cancer patients in Turkey. Eur J Oncol Nurs. 2010 Feb; 14(1): 49-54. PMid:19748316 https: //doi.org/10.1016/j.ejon.2009.07.006

[9] Sheikhi MA, Ebadi A, Talaeizadeh A, et al. Alternative Methods to Treat nausea and Vomiting from Cancer Chemotherapy. Chemother Res Pract. 2015; 818759.

[10] Herrstedt J. Antiemetics: an update and the MASCC guidelines applied in clinical practice. Nat Clin Pract Oncol. 2008 Jan; 5(1): 32-43 PMid:18097455 https://doi.org/10.1038/ncponc1021

[11] Hickok JT, Roscoe JA, Morrow GR, et al. A Phase II/III Randomized, Placebo-Controlled, Double-Blind Clinical Trial of Ginger (Zingiber officinale) for Nausea Caused by Chemotherapy for Cancer: A Currently Accruing URCC CCOP Cancer Control Study. Support Cancer Ther. 2007 Sep 1; 4(4): 247-50.

[12] Munshi A, Ni LH, Tiwana MS. Complementary and alternative medicine in present day oncology care: promises and pitfalls. Jpn J Clin Oncol. 2008 Aug; 38(8): 512-20. PMid:18682440 https: //doi.org/10.1093/jjco/hyn066
[13] Ghanbari AMA, Niknami M, AtrkarRoshan Z, et al. Effect of Adding Ginger to Routine Treatment on the Intensity of Chemotherapyinduced Nausea and Vomiting in Cancer patients who Referred to Razi Hospital, Rasht. J Ardabil Univ Med Sci. 2010; 10(4): 352-61.

[14] Mazlum S, Chaharsoughi NT, Banihashem A, et al. The effect of massage therapy on chemotherapy-induced nausea and vomiting in pediatric cancer. Iran J Nurs Midwifery Res. 2013 Jul; 18(4): 280-4.

[15] Lou Y, Yates P, McCarthy A, et al. Self-management of chemotherapy-related nausea and vomiting: a cross-sectional survey of Chinese cancer patients. Cancer Nurs. 2014 Mar-Apr; 37(2): 126-38.

[16] Beal MW. Acupuncture and related treatment modalities. Part II: Applications to antepartal and intrapartal care. J Nurse Midwifery. 1992 Jul-Aug; 37(4): 260-8. https://doi.org/10.1016/0091 -2182 (92) 90130-U

[17] Kaptchuk TJ. Acupuncture: theory, efficacy, and practice. Ann Intern Med. 2002 Mar 5; 136(5): 374-83. PMid:11874310 https: //doi .org/10.7326/0003-4819-136-5-200203050-00010

[18] Shen J, Glaspy J, Shen J, et al. Acupuncture: evidence and implications for cancer supportive care. Cancer Pract. 2001 May-Jun; 9(3): $147-50$.

[19] Lee J, Dodd M, Dibble S, et al. Review of acupressure studies for chemotherapy-induced nausea and vomiting control. J Pain Symptom Manage. 2008 Nov; 36(5): 529-44.

[20] Zwaanswijk M, Tates K, van Dulmen S, et al. Communicating with child patients in pediatric oncologyconsultations: a vignette study on child patients', parents', and survivors'communication preferences. Psychooncology. 2011 Mar; 20(3): 269-77.

[21] Basch E, Prestrud AA, Hesketh PJ, et al. Antiemetic use in oncology: Updated guideline recommendations from ASCO. American Society of Clinical Oncology Educational Book. 2012; 532-540.

[22] Ettinger DS, Armstrong DK, Barbour S, et al. Antiemesis. Journal of the National Comprehensive Cancer Network. 2012; 10: 456-85. https://doi.org/10.6004/jnccn. 2012.0047

[23] Hussein HA, Abdel Sadek BR. Effect of using acupressure P 6 alongside antiemetic medications on chemotherapy-induced nausea and vomiting among school age children. World Journal of Medical Sciences. 2013; 8(4): 373-81.

[24] Molassiotis A, Helin AM, Dabbour RS, et al. Selected treatment options for chemotherapy-induced nausea and vomiting. Alternative and Complementary Therapie. 2012 Jun; 18: 162-67.

[25] Genç A, Can G, Aydiner A. The efficiency of the acupressure in prevention of the chemotherapy-induced nausea and vomiting. 
Support Care Cancer. 2013 Jan; 21(1): 253-61. PMid:22678407 https://doi.org/10.1007/s00520-012-1519-3

[26] Rhodes VA, Johnson MH, McDaniel RW. Nausea, vomiting, and retching: the management of the symptom experience. Semin Oncol Nurs. 1995 Nov; 11(4): 256-65. https://doi.org/10.1016/S0 749-2081 (05) 80006-3

[27] Hassan G, Khalifa M, Bahbah M, et al. Effect of Guided Imagery Relaxation Session Versus Story Telling on Reducing the Intensity of Nausea and Vomiting in Children Undergoing Chemotherapy. Thesis for Master Degree, Menofia University. Egypt. 2011.

[28] Dibble SL, Luce J, Cooper BA, et al. Acupressure for chemotherapyinduced nausea and vomiting: a randomized clinical trial. Oncol Nurs Forum. $2007 \mathrm{Jul}$; 34(4): 813-20.

[29] Salama A, Khalifa M, El-Sharkawy O, et al. Effect of Therapeutic Massage on Reducing Pain and Fatigue in Children with Cancer .Thesis submitted in partial fulfillment of the requirements for master degree in pediatric nursing. Menofia University. Egypt. 2011; 60-80.

[30] Perrillat F, Clavel J, Jaussent I, et al. Family cancer history and risk of childhood acute leukemia (France). Cancer Causes Control. 2001 Dec; 12(10): 935-41.

[31] Gardani G, Cerrone R, Biella C, et al. A progress study of 100 cancer patients treated by acupressure for chemotherapy-induced vomiting after failure with the pharmacological approach. Minerva Med. 2007 Dec; 98(6): 665-8.

[32] Said ZMO. Acupressure for chemotherapy-induced nausea and vomiting in breast cancer patients: a multicenter, randomised, doubleblind, placebo-controlled clinical trial. National University. Nablus, Palestine. 2009.

[33] Sima L, Wang X. Therapeutic effect of acupuncture on cisplatininduced nausea and vomiting. Zhongguo Zhen Jiu. 2009 Jan; 29(1): 3-6.

[34] Ryan JL. Treatment of Chemotherapy-Induced Nausea in Cancer Patients. Eur Oncol. 2010; 6(2): 14-16. PMid:21984886

[35] Esmail N, Darwish D, Elsayed E, et al. Effect of progressive muscle relaxation technique versus acupressure on chemotherapy induced nausea and vomiting in leukemic children. International Journal of Current Research. 2014 July; 6(7): 7674-82.

[36] Chuang SW, Lian YH, Fang JL. Acupressure can alleviate chemotherapy-induced nausea and vomiting (CINV) Evidence and clinical application. VGH Nursing. 2014; 31: 34-42.

[37] Ezzo JM, Richardson MA, Vickers A, et al. Acupuncture-point stimulation for chemotherapy-induced nausea or vomiting. Cochrane Database Syst Rev. 2006 Apr; 19(2): CD002285.

[38] Genç F, Tan M. The effect of acupressure application on chemotherapy-induced nausea, vomiting, and anxiety in patients with breast cancer. Palliat Support Care. 2015 Apr; 13(2): 275-84. PMid:24787745 https://doi.org/10.1017/S1478951514000 248

[39] Abusaad FE, Ali WGM. Effect of point 6 acupressure on chemotherapy associated nausea and vomiting among adolescents with cancer. J Nursing Educat Practice. 2016; 6(4): 122-9. https ://doi .org/ 10.5430/jnep.v6n4p122

[40] Shen CH, Yang LY. The Effects of Acupressure on Meridian Energy as well as Nausea and Vomiting in Lung Cancer Patients Receiving Chemotherapy. Biol Res Nurs. 2017 Mar; 19(2): 145-152. PMid:28024410 https://doi .org/10.1177/10998004166838 01

[41] Byju A, Pavithran S, Antony R. Effectiveness of acupressure on the experience of nausea and vomiting among patients receiving chemotherapy. Canadian Oncol Nursing J. 2018; 28(2): 132-8. https://doi.org/10.5737/23688076282132138

[42] Wulffa B, Schmidta C, Lebmannb N, et al. Pericardium 6 accupressure as additive antiemetic therapy during chemotherapy in adolescents - A randomized placebo controlled pilot study. Eur J Med. 2009 Dec; 1(4): 205-6.

[43] Mohammed A, Elhamshary A, Khalifa M, et al. Effect of massage therapy on the occurrence of nausea and vomiting in children receiving chemotherapy, thesis submitted for partial fulfillment of Doctor degree in Pediatric Nursing, Helwan University: Cairo, Egypt. 2015; $74-82$. 